Foureur MJ, Davis D, Fenwick J, Leap N, Iedema R, Forbes I, Homer CSE. (2010) The relationship between birth unit design and safe, satisfying birth: Developing a hypothetical model, Midwifery 26: 520525.

\title{
THE RELATIONSHIP BETWEEN BIRTH UNIT DESIGN AND SAFE, SATISFYING BIRTH: DEVELOPING A HYPOTHETICAL MODEL
}

\section{ABSTRACT}

Recent advances in cross disciplinary studies linking architecture and neuroscience have revealed that much of the built environment for health care delivery may actually impair rather than improve health outcomes by disrupting effective communication and increasing patient and staff stress. This paper explores the hypothesis that many current environments built to house birthing women may similarly impact on the safety of maternity care by negatively influencing levels of stress, patterns of communication and ultimately, birth outcomes. We present evidence to support a conceptual model that describes the relationships among a set of key variables that need to be considered by researchers wishing to determine the characteristics of optimal birth environments. The conceptual model describes the relationships among this set of variables as: Safe, Satisfying Birth (SSB) is a function ( $f$ ) of the Woman's Stress (WS) and Communication with the woman (CW) multiplied by Staff Stress (SS) and Communication (SC) mediated by (/) Birth Unit Design (BUD) and Model of Care (MOC). These variables are situated within an overall context of a health system that seeks to improve safety and quality in maternity care. 


\section{INTRODUCTION}

The environment in which health care occurs has substantial effects on patient health and safety, care effectiveness, staff efficiency and morale (Ulrich \& Barach, 2006). Each year in Australia, as in many other countries, expenditure on the building or refurbishment of health facilities is considerable (around $\$ A 2$ billion). Many countries have guidelines which determine the characteristics and specifications of the environment in which health care occurs. For example, in Australia, the National Health Facility Guidelines and Post Occupancy Evaluation Guidelines (NSW Health, 2007) provide a generic set of principles and mandatory requirements to ensure the building of physical environments that support and enhance the delivery of high standards of patient care. The guidelines consider models of care, access, mobility, occupational health and safety, security, infection control and more. Recent advances in cross disciplinary studies linking architecture and neuroscience have, however, revealed that much of the built environment for health care delivery may actually impair rather than improve health outcomes by increasing patient and staff stress (Stichler \& Kirk Hamilton, 2008; Ulrich et al, 2008). Stress initiates and exacerbates illness and impacts on the quality of communication between patients and staff and between staff, and poor communication increases the risk of medical errors and adverse patient outcomes. Current guidelines on the design of health facilities are generally based on experiential knowledge and therefore may require radical revision in the light of emerging evidence.

Our hypothesis is that birth units that are optimally designed facilitate effective communication, decrease both women's and staff stress and thereby provide the best opportunity for women to experience a safe and satisfying labour and birth. Reduced staff stress also contributes to workforce retention and wellbeing, thereby addressing workforce shortages, one of the major challenges to healthcare delivery throughout the world. Future research needs to explore the complex interrelationships between architecture and neuroscience, communication, quality, risk and safety in health care. Such research requires a cross-disciplinary exploration and understanding of the many variables involved.

This paper investigates the influence of birth unit design on the quality of communication between health professionals, birthing women and their supporters ${ }^{1}$. Poor quality communication contributes to stress for birthing women, leading to changes in materno-fetal physiology, increasing the likelihood of intervention being required, and decreasing the likelihood of a safe, satisfying birth (Foureur, 2008). At

\footnotetext{
${ }^{1}$ Hereafter, reference to ‘women’ will also include their supporters
} 
the same time, birth unit design impacts on staff stress, with physiological, behavioural and cognitive consequences that may lead to impaired decision making (Altimier, 2004; Ulrich et al, 2008). We hypothesise the relationships between these elements using a conceptual model that we describe in this paper. We present our hypothesis in an effort to encourage others to explore these complex relationships and also to consider birth unit design in any research on patient safety.

\section{EVIDENCE-BASED DESIGN}

"What can rigorous research tell us about "good" and "bad" hospital design? Can improved design make hospitals less risky and stressful and promote health for patients, their families and staff? Is there scientifically credible evidence that design affects clinical outcomes and effectiveness in delivering care?" (Ulrich et al, 2008; p.2). These three questions provided a framework for a recent systematic review of 450 studies addressing evidence-based healthcare design, undertaken by Ulrich and his colleagues. Despite the growth of research in the area, few studies have used experimental designs. Those that have attempted to do so are flawed since they fail to consider that most changes of the healthcare environment alter several factors simultaneously. Studies that experimentally alter only one environmental factor (such as assessing the impact of a redesigned hand-washing facility on nosocomial infection rates, or laboratory exercises to assess the impact of noise on error rates using simulated tasks) have limited applicability in clinical settings since they neglect to consider the complex human factors, staff movement paths, visual fields, interactions with patients and families and work processes, present in real-life health environments (Ulrich et al, 2008). Most study designs are observational, with or without control groups. Reliable patterns of findings do exist, however, in relation to certain environmental factors and the weight of evidence suggests that these findings can be used to predict outcomes. The following section provides an overview of the key findings of the review.

Researchers have considered environmental studies focusing on "... patient safety issues, such as infections, falls and medical errors...other patient outcomes, such as pain, sleep, stress, depression, length of stay, spatial orientation, privacy, communication and social support and overall patient satisfaction...[and] staff outcomes, such as injuries, stress, work effectiveness and satisfaction "(Ulrich et al., 2008; p.3). Evidence of particular relevance for considering the influence of Birth Unit Design on safety in maternity care includes studies aimed at reducing stress, reducing medical errors, improving staff outcomes, alleviation of pain, increasing patient satisfaction and improving communication (Ulrich et al, 2008). 
Environmental influences on stress have been extensively studied, in particular revealing that hospital noise levels have been increasing steadily around the world since the 1960s and that noise increases stress for patients, families and staff. Noise reduction studies have addressed the use of high performance, sound-absorbing materials on ceiling and wall surfaces resulting in reduced patient stress (Ulrich et al, 2008). The current evidence also reveals that medical error rates increase sharply when there is an interruption or distraction from an unpredicted noise or where there are communication discontinuities among staff. Error rates can be reduced through addressing noise levels, increasing light and providing acuity-adaptable single patient rooms (Ulrich et al, 2008). Studies have established that high staff stress from a range of environmental stressors contributes to employee burnout and intention to leave the job, leading to workforce shortages. Several randomised controlled trials have focused on the alleviation of pain revealing the effectiveness of exposing patients to nature through window views, displaying art with nature subject matter, simulated nature views on television screens and buildingorientation and site planning to maximise access to views and daylight (Ulrich et al, 2008). For birthing women, managing the pain of labour is of prime concern, making this evidence particularly relevant for informing birth unit design.

Environmental satisfaction is a significant predictor of overall satisfaction in healthcare settings, ranking just below perceived quality of nursing and clinical care. Factors contributing to satisfaction include (but are not limited to) space, light, noise, air quality, views of nature, privacy and single rooms. One of the least studied areas includes communication/environment interactions and environmental alterations to enhance family-patient-staff communication and none of the studies located for the systematic review (Ulrich et al, 2008) were located within the environment for birth.

\section{Design of birth units}

Birth facilities are of particular interest in considering a link between design and outcomes since pregnant women are generally healthy and pregnancy and childbirth are usually considered to be normal life events rather than an illness or disease. In Australia, the National Review of Maternity Services recognised this, saying that women "should be able to feel they are in control of what is happening during pregnancy, childbirth and the postnatal period, based on their individual needs and having discussed issues fully with their care providers" (Commonwealth of Australia, 2008; p.1). Similar issues are present in other countries. Two large European studies involving over 4000 women revealed that feeling in control and women's feelings of safety and satisfaction with their experience of birth are significantly influenced by the physical environment in which labour and birth took place (Newburn \& 
Singh, 2005; Rudman et al, 2007). Of considerable concern is the knowledge that dissatisfaction with the birth experience is strongly associated with subsequent postpartum mood disorders which may have long term implications for the wellbeing of the infant as well as for the mother (Beck, 1996; Creedy et al, 2000; Maggioni et al, 2006; Murray et al, 2006).

There is increasing evidence articulating how the design and aesthetics of the spaces we inhabit, impact on our physicality, behaviour, neurophysiology and wellbeing (de Botton, 2006; Dilani, 2001; Edelstein, 2004; Fleming et al, 1984; Ulrich \& Barach, 2006). Several recent studies have considered the impact of spaces built to house birthing women outside of their homes and how these environments may impact on maternal and infant outcomes (Forbes et al, 2008; Foureur, 2008; Foureur \& Hunter, 2007; Hodnett et al, 2005; Lepori et al, 2008; Lock \& Gibb, 2003; Newburn \& Singh, 2005; Olsen \& Jewell, 2006; Symon et al, 2008a, 2008b, 2008c, 2008d; Walsh \& Downe, 2004). We have explored the findings from some of these studies in developing our hypothesis that modern birth unit design impacts on birthing women and their carers.

Birth in hospital is a relatively recent phenomenon. The move to hospital birth coincided with the medicalisation of childbirth, which has led to decades of disputed claims that the improvements in maternal and infant outcomes that occurred at around the same time were as a direct result of medical intervention (Donnison, 1977; Fahy, 2008a; Shorter, 1983; Tew, 1990). A correlation of events is undeniable and the result has been that hospital birth spaces now function as a technology of biomedicine, with childbirth seen as a medical condition. Institutional birth spaces are designed to accommodate this focus. According to architect Lepori (1994) “...the organisation of the entire setting is a function of the patterns of movement that occur during intervention" (p.4). Studies of women who have given birth at home show that they seldom give birth in the bedroom, but more often in their sitting room where they select an empty and protected area, never exposing themselves at the centre of the scene (Lepori, 1994). The birth room built to house women in hospitals is clearly a bedroom. It is not the cosy, private nest that women create at home, but a stage on which the woman becomes a spectacle under constant surveillance and control (Davis-Floyd, 2001; Davis, 2006). Davis and Walker (2009b) regard the modern hospital birth room as a place that informs the woman, her supporters and carers that she is vulnerable and endangered and this is what she becomes: 'a woman at risk of peril and death rather than a woman in rapture to birth and life' (Davis \& Walker, 2009b). So the labouring woman and those around her become fearful and watch, waiting for the first sign that things have gone awry (Hood et al, 2008). Lepori $(1992,1994)$ has raised concerns about poor total environments for birth 
in hospitals. She has recognised that poor physical environments are a major contributor to creating pathological rather than physiological places for labour and birth. These concepts inform our exploration of how birth space influences aspects of care and communication.

\section{COMMUNICATION IN HEALTH CARE}

Effective communication is essential for the delivery of high quality, safe patient care (Committee on Quality Health Care in America, 2001; Leonard et al, 2004). Communication failures are an extremely common cause of inadvertent patient harm (Leonard et al, 2004). A recent report on incident management in the New South Wales (Australia) health care system cites the main cause of critical incidents (that is, adverse events such as an incorrect procedure leading to patient harm), as being poor and inadequate communication between clinicians and patients (NSW Heath, 2005). Our hypothesis includes an understanding that the birth environment impacts on the communication styles between the woman and her carers and between carers (Hunter, 2000; 2003).

\section{Models of care and communication}

Much midwifery research has focused on setting up and evaluating the effect of continuity of midwifery care on maternity outcomes, including issues of safety and quality. The evidence from a large systematic review of this research reveals that changing to a model of care that enhances continuity from the perspective of the woman, improves the quality of care in that women are more satisfied (Hatem et al, 2008). This model of care is also more likely to result in women experiencing a spontaneous vaginal birth, and for their babies to start life in an optimal condition (Hatem et al, 2008). However there are several aspects of research into models of care that have received little comment. Few studies systematically explore the patterns of communication enabled within different models of care and fewer still assess the alterations to the environment that are facilitated by the midwives working in this way. Changes to the birth environment involve seemingly simple features such as turning down bright lights, moving the bed away from the centre of the room, adding floor mats or other comfortable furniture for supporting the woman as she needs, encouraging the woman to bring her favourite music with her or objects from home that have special meaning for her, and so on. Clearly midwives alter the environment to accommodate the needs of each woman. It is not known therefore whether manipulating the birth environment in this way contributes to the positive outcomes seen in models of care research. Several recent studies have examined the impact of different birth environments on the decision making and communication behaviour of midwives who move between home, birth centre and 
hospital settings (Hunter, 2000; Hunter, 2003; Miller, 2008). These studies reveal that different environments exert a powerful and unintended pressure on the midwives to conform to unwritten rules of conduct and styles of communication that change according to the birth environment. Midwives interviewed for these studies reported changing their communication styles depending on the location in which they found themselves, even if it was with the same woman transferred from one location to another. So 'Model of care' needs to be considered in any research into the impact of the birth environment on safe, satisfying birth. From a design perspective, architects and hospital planners are interested in the model of care to be enacted within the spaces they build, since the space is ideally designed to accommodate the model.

\section{Design and communication}

Design of space and the influence on communication has been explored in the postnatal period of maternity care. Lock and Gibb (2003) studied women who had returned home after giving birth in hospital and found that spatiality or felt space was a fundamental concept. Women who had recently given birth reacted to particular spaces in certain ways. Components of spatiality expressed through the power of place included the physical environment, notions of control, having adequate time and feeling and being emotionally and physically safe. The study highlighted differences between care at home, where women felt safe in a familiar environment, and in hospital, a foreign place, where they experienced alienation and disempowerment. There are important insights to be gained from this study that we have applied to our subsequent research on birth unit design, particularly as the vast majority of women give birth in hospital. We propose that if hospital space is seen as alienating and disempowering, communication will be affected, both between women and health care providers and between providers themselves.

A small number of studies have examined the relationship between design and communication between maternity care providers. Williams (2003) explored the critical features of positive communication occurring at the central 'desk' in birth units where midwives congregated to share real-time and remembered narratives about labouring and birthing women. The sharing of their stories enabled concepts of risk and safety to be explored and in so doing management plans for individual women were subsequently refined. Many new birth units have removed the communal 'desk' and now have computer stations in each birth room. The opportunity for effective, collaborative communication may have been lost. Other areas where opportune communication occurs include the tea room, office and 
corridors (Hunt \& Symonds, 1995). A recent, three year multi-method/multi-site study in the UK examined the impact of maternity unit design on satisfaction levels and staff perceptions of work performance (Symon et al, 2008a; 2008b; 2008c; 2008d). This work provided additional insights for refining the principles of birth unit design for our study. In particular, we realised that we had neglected to adequately consider the contribution of staff comfort and the means of facilitating communication between staff as a design component needing to be assessed in our pilot work (Foureur et al, 2010a; Foureur et al, 2010b).

\section{THE SAFE SATISFYING BIRTH HYPOTHESIS}

Our group has been studying birth unit design in recent years and through this work we have developed the safe satisfying birth hypothesis (Davis \& Walker, 2009a; Foureur, 2008). Recently, we undertook a study to assess birth units for their ability to promote safe, satisfying birth (SSB) by developing and testing a Birth Unit Design Spatial Evaluation Tool (BUDSET) (Forbes et al, 2008; Foureur et al, 2010a; Foureur et al, 2010b). The BUDSET was developed using evidence from the literature and focus groups with midwives and key informant interviews with architects and midwifery researchers and academics. The discriminating ability of the BUDSET was then quantitatively assessed in eight maternity units to provide an overall Optimality Score for each birth unit. We are currently testing the content and construct validity of the BUDSET with women who are either pregnant or who have recently given birth, and with their midwives. These prior studies form the foundation for our safe satisfying birth hypothesis.

The hypothesis applies the theory of Birth Territory co-developed by Foureur in a recent book (Fahy et al, 2008b). Birth Territory recognises the physical territory of the birth space over which jurisdiction or power is claimed for the woman and builds on work of philosophers including Foucault (Fahy, 2008a; Foucault, 1980) and the Supportive Design Theory of Ulrich (1997). We have developed a qualitative conceptual model to indicate the complex, non-linear, inter-relationships between the key variables in our hypothesis (Figure 1).

Our hypothesis and its conceptual model recognise the complexity of birth and places the woman and her safety and perception of wellbeing as the goal of maternity care. Collectively our group has developed considerable expertise over decades of independent research into the individual components of the Safe, Satisfying Birth Hypothesis (Davis \& Walker, 2009b; Forbes, 2005; Homer et al, 2001; Rowley [Foureur] et al, 1995). We have come to realise we now have to combine our research in new cross- 
disciplinary ways in order to deepen our understanding of the worldwide phenomenon of rising intervention rates and decreasing safety and satisfaction experienced by birthing women. We offer the hypothesis that safe, satisfying birth is a function of the level of stress experienced by a woman, that can be magnified or ameliorated by the patterns of communication she experiences from those around her and caring for her; that her resulting physiological state may be further impacted upon by the relationship she has with her carers, who bring with them their own experiences of stress and communication; and all of these interactions will be impacted on by particular birthing environments and within particular models of care

We offer the hypothesis and model as a starting point for researchers who have an appreciation of the complexity of birth and the ability to bring together colleagues from a range of disciplines to explore the pre-requisites for Safe, Satisfying Birth, in new ways.

\section{CONCLUSION}

Pregnancy and childbirth account for the largest number of hospital admissions in many developed countries like Australia. Care is provided over a prolonged period, on multiple occasions and shared between disciplines, such as, midwifery, obstetrics, paediatrics, nursing, neonatology and allied health. Such complex clinical environments, where care is often shared and fragmented between multiple health professionals, contribute to communication problems and subsequent difficulties in ensuring safe and reliable systems of care (ACSQHC, 2004; Kohn et al, 2001). Numerous inquiries into health care organisations initiated by concerns raised about unsafe care have recognised communication features as crucial elements in organisational failings. For example, the Inquiry into King Edward Memorial (maternity) Hospital in Western Australia highlighted significant communication breakdown, including: failure to provide an adequate explanation of poor outcome; failure to include a woman and her partner in decisions; and a lack of sensitivity, respect, dignity and support (ACSQHC, 2002; Douglas et al, 2001). Improving communication will reduce adverse events and improve patient safety, thus resulting in economic and social benefits. While communication has been repeatedly recognised as fundamental to safe health care, limited efforts have been made to understand the complex relationships between communication and environment. Our hypothesis provides a conceptual model to deepen the understanding of the complex relationships between a number of significant factors ensuring patient safety and could provide a useful platform for further research. We hope this paper will stimulate others to explore these important issues. 


\section{REFERENCES}

ACSQHC. 2002. Lessons from the Inquiry into Obstetrics and Gynaecology Services at King Edward Memorial Hospital 1990-2000. Canberra: Australian Council for Safety and Quality in Health Care.

ACSQHC. 2004. Setting the Human factor standards for health care: Do lessons from aviation apply? A report on the human factors in healthcare workshop Paper presented at the Sixth International Australian Aviation Psychology Symposium.

Altimier, L. 2004. Healing Environments for Patients and Providers. Newborn and Infant Nursing Reviews 4, 89-92.

Beck, C. 1996. A meta-analysis of the relationship between postpartum depression and infant temperament. Nursing Research, 45, 225-230.

Committee on Quality Health Care in America. 2001. Crossing the quality chasm: a new health system for the 21st century. Washington DC: National Academy Press.

Commonwealth of Australia. 2008. Improving Maternity Services in Australia: A Discussion Paper from the Australian Government. Canberra: Commonwealth of Australia.

Creedy, D. K., Scochet, I. M., \& Horsfall, J. 2000. Childbirth and the development of acute trauma symptoms: Incidence and contributing factors. Birth, 27, 104-111.

Davis-Floyd, R. 2001. The technocratic, humanistic, and holistic paradigms of childbirth. International Journal of Gynecology \& Obstetrics, 75, S5-S23.

Davis, D. 2006. The politics of practice: Case-loading midwifery practice in New Zealand (PhD thesis). Sydney: University of Technology Sydney.

Davis, D., \& Walker, K. 2009a. The corporeal, the social and space/place: Exploring intersections from a midwifery perspective. Gender, Place and Culture: A Journal of Feminist Geography, (in Press).

Davis, S., \& Walker, K. 2009b. Re-discovering the material body through an exploration of theories of embodiment. Midwifery, DOI: 10.1016/j.midw.2008.10.004 (in press).

de Botton, A. 2006. The Architecture of Happiness: The Secret Art of Furnishing Your Life. New York: Penguin.

Dilani, A. (Ed.). 2001. Design and Health - The Therapeutic Benefits of Design. Svensk Byggtjänst: Proceedings of the International Academy for Health and Design.

Donnison, J. 1977. Midwives and Medical Men. London: Heinemann. 
Douglas, N., Robinson, J., \& Fahy, K. 2001. Inquiry into Obstetrics and Gynaecological Services at King Edward Memorial Hospital. Perth: Government of Western Australia.

Edelstein, E. 2004. Neuroscience and Architecture: Health Care Facilities. Woods Hole, Erik Jonsson Center of the National Academy of Sciences.

Fahy, K. 2008a. Power and the social construction of birth territory. In K. Fahy, Foureur, M., Hastie, C. (Ed.), Birth Territory and Midwifery Guardianship: Theory for Practice, Education and Research (pp. 3-10). Oxford: Elsevier.

Fahy, K., Foureur, M., Hastie, C. 2008b. Birth Territory and Midwifery Guardianship: Theory for Practice, Education and Research. Oxford: Elsevier.

Fleming, R., Baum, J., \& Singer, J. 1984. Toward an integrative approach to the study of stress. Journal of Personality and Social Psychology, 46, 939-949.

Forbes, I. 2005. Hospital Healing Havens Hospitals \& Healthcare, June, 26 -28.

Forbes, I., Homer, C., Foureur, M., \& Leap, N. 2008. Birthing Unit Design: Researching New Principles. Design \& Health Scientific Review, October, 47-53.

Foucault, M. 1980. Power/knowledge: selected interviews. New York: Pantheon.

Foureur, M. 2008. Creating birth space to enable undisturbed birth. In K. Fahy, Foureur, M., Hastie, C. (Ed.), Birth Territory and Midwifery Guardianship: Theory for Practice, Education and Research (pp. 57-77). Oxford: Elsevier.

Foureur, M., Hunter, M. 2007. The Place of Birth. In S. Pairman, Pincombe, J., Thorogood, C., Tracy, S. (Ed.), Midwifery - Preparation for Practice. Sydney: Elsevier.

Foureur, M., Leap, N., Davis, D., Forbes, I., \& Homer, C. 2010a. Developing the birth unit design spatial evaluation tool (BUDSET) in Australia - A qualitative study Health Environments Research \& Design Journal (in press).

Foureur, M., Leap, N., Davis, D., Forbes, I., \& Homer CSE. 2010b. Testing the Birth Unit Design Spatial Evaluation Tool (BUDSET). Health Environments Research and Design Journal (in press).

Hatem, M., Sandall, J., Devane, D., Soltani, H., \& Gates, S. 2008. Midwife-led versus other models of care for childbearing women. Cochrane Database of Systematic Reviews, Issue 4. Art. No: CD004667. DOI: 10.1002/14651858.CD004667.pub2.

Hodnett, E., Downe, S., Edwards, N., \& Walsh, D. 2005. Home-like versus conventional institutional settings for birth. Cochrane Database of Systematic Reviews, Issue 1. Art. No: CD000012. DOI: 10.1002/14651858.CD000012.pub2. 
Homer, C., Davis, G., Brodie, P., \& et al. 2001. Collaboration in maternity care: a randomised controlled trial comparing community-based continuity of care with standard hospital care. British Journal of Obstetrics and Gynaecology, 108, 16-22.

Hood, L., Fenwick, J., \& Butt, J. 2008. A Story of Scrutiny and Fear: Australian midwives' experiences of an external review of obstetric services, being involved with litigation and the impact on clinical practice. Midwifery, (in press).

Hunt, S., \& Symonds, A. 1995. The Social Meaning of Midwifery. New York: Palgrave MacMillan.

Hunter, M. 2000. Autonomy, clinical freedom and responsibility: the paradoxes of providing intrapartum midwifery care in a small maternity unit as compared with a large obstetric hospital. Unpublished MA Thesis. Massey University, Palmerston North, New Zealand.

Hunter, M. 2003. Autonomy, clinical freedom and responsibility. In M. Kirkham (Ed.), Birth centres: a social model for maternity care. London: Elsevier Science.

Kohn, L., Corrigan, J., \& Donaldson, M. (Eds.). 2001. To Err is Human: Building a Safer Health Care System. Washington: Institute of Medicine: National Academy Press.

Leonard, M., Graham, S., \& Bonacum, D. 2004. The human factor: the critical importance of effective teamwork and communication in providing safe care Quality \& Safety in Health Care, 13, i85-i90.

Lepori, B. 1992. La nascita e i suoi luoghi. Como: Red edizioni.

Lepori, B. 1994. Freedom of movement in birth places. Children's environments, 11, 81-87.

Lepori, B., Foureur, M., \& Hastie, C. 2008. Mindbodyspirit Architecture: Creating birth space'. In K. Fahy, M. Foureur \& C. Hastie (Eds.), Birth Territory and Midwifery Guardianship (pp. 95-112). Oxford: Elsevier.

Lock, L. R., \& Gibb, H. J. 2003. The power of place. Midwifery., 19, 132-139.

Maggioni, C., Margola, D., \& Filippi, F. 2006. PTSD, risk factors, and expectations among women having a baby: A two-wave longitudinal study. Journal of Psychosomatic Obstetrics and Gynaecolology. 27, 81-90.

Miller, S. 2008. First Birth at Home or in Hospital in Aotearoa/New Zealand: Intrapartum Midwifery Care and Related Outcomes (Master Thesis). Wellington: Graduate School of Nursing, Midwifery and Health, Victoria University of Wellington.

Murray, L., Halligan, S., Adams, G., Patterson, P., \& Goodyer, I. 2006. Socioemotional development in adolescents at risk for depression: the role of maternal depression and attachment style. Development \& Psychopathology. 18, 489-516. 
Newburn, M., \& Singh, D. 2005. Are Women Getting the Birth Environment They Need? A Report of a National Survey of Women's Experiences London: National Childbirth Trust.

NSW Health. 2007. NSW Health Facility Guidelines: Post Occupancy Evaluation Guideline - Final Issue February 2007. Sydney: NSW Health.

NSW Heath. 2005. Patient Safety and Clinical Quality Program. First report on incident management in the NSW public health system 2003-2004. Sydney: NSW Department of Health.

Olsen, O., \& Jewell, D. 2006. Home versus hospital birth. (Cochrane Review). Cochrane Database of Systematic Reviews (Issue 4).

Rowley [Foureur], M. J., Hensley, M. J., Brinsmead, M. W., \& Wlodarczyk, J. H. 1995. Continuity of care by a midwife team versus routine care during pregnancy and birth: a randomised trial. Medical Journal of Australia, 163, 289-193.

Rudman, A., EL-Khouri, B., \& Waldenström, U. 2007. Women's satisfaction with intrapartum care: A pattern approach. Journal of Advanced Nursing, 59, 474-487.

Shorter, E. 1983. A history of women's bodies. London: A Lane.

Stichler, J., \& Kirk Hamilton, D. 2008. Theoretical and Conceptual Frameworks in Research and Practice. Health Environments Research and Design Journal, 1, 4-6.

Symon, A., Paul, J., Butchart, M., Carr, V., Dugard, P. 2008a. Maternity unit design study Part 2: Perceptions of space and layout. British Journal of Midwifery, 16, 110-114.

Symon, A., Paul, J., Butchart, M., Carr, V., Dugard, P. 2008b. Maternity unit design study Part 3: Environmental comfort and control. British Journal of Midwifery, 16, 167-171.

Symon, A., Paul, J., Butchart, M., Carr, V., Dugard, P. 2008c. Maternity unit design study Part 4: Midwives' perceptions of staff facilities. British Journal of Midwifery, 16, 228-231.

Symon, A., Paul, J., Butchart, M., Carr, V., Dugard, P. 2008d. Maternity unit design: Background to multisite study in England. British Journal of Midwifery, 16, 29-33.

Tew, M. 1990. Safer Childbirth? A Critical History of Maternity Care. London: Chapman and Hall.

Ulrich, R. 1997. A theory of supportive design for health care facilities. Journal of Healthcare Design, IX, 3-7.

Ulrich, R., \& Barach, P. 2006. Designing Safe Healthcare Facilities - What are the data and where do we go from here? Paper presented at the Healthcare Environments Research Summit.

Ulrich, R., Zimring, C., Xuemei Z, DuBose, J., Seo, H., Choi, Y., et al. 2008. Evidence-Based Healthcare Design. Health Environments Research \& Design, 1, 61-125. 
Walsh, D., \& Downe, S. 2004. Outcomes of free-standing, midwife-led birth centers: A structured review. Birth, 31, 222.

Williams, H. 2003. Storied Births: Narrative and Organisational Culture in a Midwifery-led Birth Centre. Unpublished MSc Thesis. Kings College London. 
Figure 1: Qualitative conceptual model for Safe Satisfying Birth (SSB)

$S S B=f(W S+C W) \times(S S+S C) /(B U D+M O C)^{*}$

*The conceptual model describes the relationships among this set of variables as: Safe, Satisfying Birth (SSB) is a function ( $f$ ) of the Woman's Stress (WS) and Communication with the woman (CW) multiplied by Staff Stress (SS) and Communication (SC) mediated by (/) Birth Unit Design (BUD) and Model of Care (MOC). These variables are situated within an overall context of a health system that seeks to improve safety and quality in maternity care. 